\title{
The Problem of Imaginative Resistance ${ }^{*}$
}

\author{
Shen-yi Liao \& Tamar Szabó Gendler \\ The Routledge Companion to the Philosophy of Literature (forthcoming) ${ }^{\dagger}$
}

The problem of imaginative resistance holds interest for aestheticians, literary theorists, ethicists, philosophers of mind, and epistemologists. In this entry, we present a somewhat opinionated overview of the philosophical discussion to date. We begin by introducing the phenomenon of imaginative resistance (section 1). We then review existing responses to the problem (section 2), giving special attention to recent research directions (section 3). Finally, we consider the philosophical significance that imaginative resistance has-or, at least, is alleged to have-for issues in moral psychology, theories of cognitive architecture, and modal epistemology (section 4).

\section{Imaginative Resistance}

As a first pass, imaginative resistance occurs when an otherwise competent imaginer finds it difficult to engage in some sort of prompted imaginative activity. Many contemporary authors trace the idea of imaginative resistance to a remark that appears near the end of David Hume's "Of the Standard of Taste" (1757). Hume writes:

Where speculative errors may be found in the polite writings of any age or country, they detract but little from the value of those compositions. There needs to be but a certain turn of thought or imagination to make us enter into all the opinions which then prevailed and relish the sentiments or conclusions derived from them. But a very violent effort is requisite to change our judgment of manners, and excite sentiments of approbation or blame, love or hatred, different from those to which the mind from long custom has been familiarized... I cannot, nor is it proper that I should, enter into such [vicious] sentiments.

\footnotetext{
* We thank Tyler Doggett and Eric Mandelbaum for insightful comments on an earlier draft of this chapter ${ }^{\dagger}$ Penultimate Version. For citation and reference, please see the definitive and final version forthcoming in Gibson, J and Carroll, N., eds., The Routledge Companion to the Philosophy of Literature. New York: Routledge.
} 
This contrast - between (a) easy cases where "there needs be but a certain turn of thought or imagination" to "enter into... opinions... and sentiments" of another time, place, or imaginary context, and (b) challenging cases where "a very violent effort is requisite to... excite sentiments... different from those to which the mind... has been familiarized" - lies at the heart of the phenomenon under discussion. Discussions of imaginative resistance have focused on identifying other characteristics - both "upstream" and "downstream" - that further distinguish easy cases from challenging ones.

Upstream questions ask: is there an interesting independent way of distinguishing between easy and challenging cases of prompted imaginative activity, on the basis of either form or content? (Hume, for example, seems to suggest that challenging cases involve deviations in moral content, whereas easy cases do not.) Downstream questions ask: are there additional normatively-significant costs and benefits associated with being an easy or challenging case? (Hume, for example, seems to suggest that works that give rise to challenging cases are thereby aesthetically compromised, whereas works that give rise only to easy cases are not.)

We can see this contrast at play by focusing on a widely-discussed contemporary example (Weatherson 2004: 1):

Death on a Freeway. Jack and Jill were arguing again. This was not in itself unusual, but this time they were standing in the fast lane of I-95 having their argument. This was causing traffic to bank up a bit. It wasn't significantly worse than normally happened around Providence, not that you could have told that from the reactions of passing motorists. They were convinced that Jack and Jill, and not the volume of traffic, were the primary causes of the slowdown. They all forgot how bad traffic normally is along there. When Craig saw that the cause of the bankup had been Jack and Jill, he took his gun out of the glovebox and shot them. People then started driving over their bodies, and while the new speed hump caused some people to slow down a bit, mostly traffic returned to its normal speed. So Craig did the right thing, because Jack and Jill should have taken their argument somewhere else where they wouldn't get in anyone's way.

The final sentence of the story - "Craig did the right thing, because Jack and Jill should have taken their argument somewhere else where they wouldn't get in anyone's way" - seems to gives rise to at least four distinct resistance-related puzzles, each associated with a typical reaction to the sentence (Weatherson 2004, Walton 2006). (1) One has difficulty imagining that Craig's action is really morally right. This raises the imaginability puzzle: why, in certain cases, do readers display a reluctance or inability to engage in some mandated act of imagining, so that typical invitations to make-believe are insufficient? (2) One has difficulty accepting that it is 
fictional, or true in the story world, that Craig's action is really morally right. ${ }^{1}$ This gives rise to the fictionality puzzle: why, in certain cases, does the default position of authorial authority break down, so that mere authorial say-so is insufficient to make it the case that something is true in a story? (3) One experiences a sense of jarring confusion in response to the sentence. This raises the phenomenological puzzle: why do certain propositions tend to evoke a particular phenomenology, sometimes described as 'doubling of the narrator' or 'pop-out' (Gendler 2000, 2006a)? (4) One thinks that the story would be aesthetically superior if its final sentence were deleted. This gives rise to the aesthetic value puzzle: why, in certain cases, are texts that evoke other sorts of imaginative resistance thereby aesthetically compromised?

Questions (1), (2) - and to some extent (3) - are upstream questions: they seek to identify the source(s) of resistance-like phenomena. Question (4) - and to some extent (3) - is a downstream question: it seeks to identify some of their consequences.

Before continuing, it may be helpful to distinguish cases that give rise to imaginative resistance from cases that give rise to the related phenomenon of hermeneutic recalibration (Liao 2013). The latter is a common literary technique of temporarily puzzling the reader so as to cause her to reconsider and reinterpret the work. In cases of hermeneutic recalibration, one eventually comes to a relatively stable reading of the work that allows one imagine and accept as fictional the proposition(s) expressed by the initially jarring sentence or passage. This literary technique is common in magical realist novels where, for example, one might originally find jarring the claim that a character was literally washed into this world on a great tide of tears, but find later that the perplexity disappears when one recognizes that that magical realist worlds come with their own sets of rules. Imaginative resistance differs from hermeneutic recalibration in its persistence; the perplexity remains even after one has fully digested the work.

Even if we restrict our discussion to cases involving persistent perplexity, there are ongoing disagreements about the scope of the phenomenon. Tamar Szabó Gendler $(2000,2006 a)$ argues for the centrality of moral deviance to resistance phenomena. Kendall Walton $(1994,2006)$ argues that imaginative resistance also arises with aesthetic deviance. Brian Weatherson (2004) argues that imaginative resistance arises with deviance in epistemic evaluations, deviance in attributions of mental states, deviance in attributions of content, deviance in ontology, and deviance in constitution. Stephen Yablo (2002) argues that imaginative resistance arises with response-dependent descriptive concepts, such as shape. As we will see, this disagreement about scope drives some disagreements between about both upstream

\footnotetext{
${ }^{1}$ Reflections on one's responses can help make the fictionality assessment explicit. Normally, I take what the text explicitly says to be indicative of what is true in the fiction. So when the text asserts $\varphi$, I typically judge $\varphi$ to be fictional. However, as Matravers (2003) suggests, I respond differently to sentences that evoke imaginative resistance: I recast what is asserted as what the narrator (or a fictional character) thinks. When the text asserts $\varphi$, I judge only the narrator thinks that $\varphi$ to be fictional, and not that $\varphi$ itself is fictional.
} 
and downstream questions, and - in some cases - gives rise to skepticism about the very existence of a philosophical problem in the vicinity.

\section{First Wave}

Our review of responses to the problem of imaginative resistance proceeds roughly chronologically. There are multiple points of disagreement. Authors disagree over the scope of the problem (as we have just seen), over the mechanisms for evoking imaginative resistance, over the psychological components implicated in imaginative resistance, and so on. However, in an effort to construct a narrative of how this literature developed, we will focus in this section on the disagreement over the nature of imaginative resistance. We thus categorize the responses into three kinds: cantian theories, wontian theories, and eliminativist theories. ${ }^{2}$

\subsection{Cantian Theories}

Cantian theories maintain that imaginative resistance at its core can be traced to the impossibility of engaging in some sort of prompted imaginative activity: One simply can't imagine as one has been invited to. Cantian theories typically take the fictionality puzzle to be fundamental, suggesting that one experiences the jarring phenomenology and the imaginative inability associated with imaginative resistance because the default position of authorial authority has broken down.

The development of cantian theories can be traced to Walton $(1990,1994)$. Walton (1994: 35) offers a particularly clear statement of the fundamentality of the fictionality puzzle (and also offers some speculation about the upstream question):

In [Walton (1990)] I suggested that [imaginative resistance] obtains at the level of mere representation, i.e. when it comes to ascertaining what is true-inthe-fictional-world, quite apart from what we might take to be the work's message or moral or any ambition or tendency it might have to change or reorganize our beliefs or attitudes or behavior or instincts. My suggestion was, very briefly, that when we interpret literary and other representational works of art we are less willing to allow that the works' fictional worlds deviate from the real world in moral respects than in nonmoral ones.

Walton is skeptical about the existence - as possible worlds - of story worlds that fundamentally deviate from the real world in moral respects. He acknowledges that there could be characters in a story who, for example, believe that simple female infanticide is morally right; but he denies that simple female infanticide could really

\footnotetext{
${ }^{2}$ The following taxonomy and characterization of cantian and wontian theories originate from Gendler (2006) and Weinberg and Meskin (2006), and draw from Gendler (2009). Others who have contributed this taxonomic framework include Tyler Doggett, Andy Egan, and Kelly Trogdon.
} 
be morally right - even in a purely fictional story world. ${ }^{3}$ And if there is no possible story world where $\mathrm{X}$ is morally right, an author cannot make it true in a story that $\mathrm{X}$ is morally right (fictionality). Since what is fictional constrains what is imaginable in the context of interacting with a work, readers also cannot imaginatively engage with the prompted X-content (imaginability).

Building on insights from Walton (1994) and Yablo (2002), Weatherson (2004) proposes a cantian theory that focuses on the impossibility of deviant dependence relationships. On Weatherson's cantian theory, imaginative resistance arises when stories violate a principle that he calls Virtue - namely, that "if $p$ is the kind of claim that, if true, must be true in virtue of lower-level facts, and if the story is about these lower-level facts, then it must be true in the story that there is some true proposition $\mathrm{r}$ which is about these lower-level facts such that $\mathrm{p}$ is true in virtue of $\mathrm{r}$ " (Weatherson 2004: 18). For example, since moral facts depend on nonmoral facts, once the author stipulates the relevant nonmoral facts (e.g. physiological and psychological facts about pain and pleasure) that hold in a story world, she has no further say about the moral facts that hold in that story world. Authorial authority breaks down when it comes to stipulating dependence relationships that are true in a story. It is the incoherence between higher-level (e.g. moral) and lower-level (e.g. physiological and psychological) facts that evokes readers' experiences of jarring phenomenology and imaginative inability.

An alternative cantian theory can be found in Weinberg and Meskin (2006). Drawing on work by Shaun Nichols about the nature of propositional imagination (Nichols and Stich 2003, Nichols 2004, Nichols 2006a), Jonathan Weinberg and Aaron Meskin suggest that imaginative resistance arises from a conflict between different cognitive systems. In cases of moral deviance, for example, there is a conflict between an input system that takes in the explicitly stipulated moral deviance as its content and a moral evaluation system that makes an independent judgment on the basis of the fictional scenario's relevant nonmoral features (roughly Weatherson's lower-level facts.) What sets Weinberg and Meskin's cantian theory apart from others is how it handles cases where readers do not experience jarring phenomenology or imaginative inability in response to fictional impossibilities. According to Weinberg and Meskin, in these cases, either the input system or the moral system is locally suspended, so no psychological conflict arises.

\subsection{Wontian Theories}

Wontian theories maintain that imaginative resistance can be traced to an unwillingness to engage in some sort of prompted imaginative activity: One simply won't imagine as one has been invited to. Wontian theories typically take the

\footnotetext{
${ }^{3}$ Strictly speaking, Walton does not commit himself to the impossibility of fictional moral deviance, only something very close to it: "I have learned never to say never about such things. Writers of fiction are a clever and cantankerous lot who usually manage to do whatever anyone suggests can't be done, and philosophers are quick with counterexamples. But in this instance counterexamples are surprisingly difficult to come by" (Walton 1994: 38).
} 
imaginability puzzle to be fundamental. According to them, the default position of authorial authority (that is, what the implied author says is true in the story world) breaks down because the reader finds it improper to engage in the imaginative activity that is prompted, such as imaginatively taking on morally deviant attitudes.

Gendler (2000) is the first contemporary author to propose a wontian theory. In response to cantian criticisms, Gendler (2006a) further refines the theory. On the refined theory, classic cases of imaginative resistance do involve an impossibility, for roughly the reasons that Weatherson identifies, but the impossibility is due to the reader's unwillingness to engage in such imaginative enterprises. Specifically, one won't imaginatively take on morally deviant attitudes that could infect one's attitudes toward real-world persons and circumstances. As Gendler (2000: 77) originally puts the point: "my hypothesis is that cases that evoke genuine imaginative resistance will be cases where the reader feels that she is being asked to export a way of looking at the actual world which she does not wish to add to her conceptual repertoire".

Gregory Currie (2002) and Dustin Stokes (2006) develop distinctive psychologicallybased wontian theories. According to both Currie and Stokes, in addition to the familiar attitude of cognitive imagination, an imaginative analogue to belief, there exist attitudes of conative imagination, an imaginative analogue to desire, which Currie refers to as desire-like imagination and Stokes refers to as value-like imagination (where values are second-order desires or desires about desires (cf. Lewis 1989)). On both accounts, while we easily cognitively imagine what we do not believe, we do not easily conatively imagine what we do not desire or value. Imaginative resistance arises when one won't conatively imagine in ways that diverge from one's actual desires or values. For example, one won't imaginatively take on the morally deviant attitude that female infanticide (without further explanation) is acceptable because one does not actually desire or value female infanticide (without further explanation).

\subsection{Eliminativist Theories}

As the imaginative resistance literature moves toward maturity, both cantians and wontians have attempted to incorporate insights from the other. But despite their increasingly subtle disagreements about the nature of imaginative resistance, both cantians and wontians accept the existence of the phenomenon.

In contrast, eliminativist theories maintain that there is no such a thing as imaginative resistance per se. Rather, they maintain, the appearance of a philosophical problem arises from the bizarre so-called stories that philosophers have concocted. Nothing like the imaginability, fictionality, or phenomenological puzzles arises with narratives and imaginings in ordinary non-philosophical contexts.

Cain Todd (2009: 191) gives the clearest statement of the eliminativist position: 
For fictional worlds in general do not consist of isolated, a-contextual single propositions, and the few that have been mustered-or rather invented-in the literature as supposed examples of the phenomenon of imaginative resistance are testimony rather to the paucity of such cases in genuine fiction, whatever the situation might be in respect of propagandistic, simplistic and straightforwardly poor creations of impoverished skill and imagination.

Building on observations from Michael Tanner (1994), Mary Mothersill (2003), and Kathleen Stock (2005), Todd argues that imaginative resistance can only be found in the poor creations of impoverished skill and imagination that have served as examples in the philosophical literature. It is because they have focused on single propositions divorced from context - or one-page stories constructed for the sake of making a philosophical point - that philosophers think there is a problem to be explained. Eliminativists contend that propositions that are alleged to evoke imaginative resistance typically cease to do so once appropriate context is given (modulo some relativity regarding general imaginative capacity). ${ }^{4}$

To be clear, eliminativist theories do not claim that imaginative resistance is philosophically uninteresting. What they maintain is there is no unique problem here. On their accounts, any philosophical interest that remains, once we reject the problematic presuppositions, can be dissolved into existing philosophical problems. For example, the aesthetic puzzle may survive as an instance of a broader debate over ethical criticism of art (which we will discuss in section 4.2).

\section{Second Wave}

Since roughly 2010, philosophers writing on the topic have begun to question substantive and methodological assumptions in earlier responses to the problem of imaginative resistance. In so doing, they also suggest that serious revisions are needed to improve our understanding of this phenomenon.

\subsection{The Importance of Context}

The first challenge that recent works pose concerns subject-matter. In characterizing imaginative resistance, earlier responses tended largely to neglect context, focusing instead on particular isolated propositions and passages within a (constructed) story. We can see this focus in cantian theories' attempts to locate propositions that cannot be true in a story world and in wontian theories' attempts to locate propositions that people do not desire or value. Indeed, this focus is central to eliminativist theories' criticism of cantian and wontian theories.

\footnotetext{
${ }^{4}$ In fact, Todd (2009: 196) speculates the philosophers, especially moral realists, may be especially susceptible to imaginative resistance given the salience of moral considerations and their theoretical commitments. The problem of imaginative resistance is thus, on Todd's view, doubly artificial and peculiar to philosophers.
} 
The rethinking of this focus is prevalent in recent responses to the problem of imaginative resistance (e.g. Brock 2012). Many of these philosophers agree with eliminativists that limited philosophical insight can be gained from examining imaginative responses to acontextual propositions. However, they also think that taking context more thoroughly into account introduces its own set of resistancerelated issues, and more importantly, increasingly sophisticated answers to the upstream questions.

One notable strand explores the role of genre in evoking or dissipating imaginative resistance (Weinberg 2008, Nanay 2010, Liao 2011, Willard manuscript). The same proposition may give rise to imaginability, fictionality, or phenomenological puzzles in a story of one genre, but not in a story of a different genre. For example, a physically impossible proposition might evoke imaginative resistance in a realistic story, but not in a science-fiction story. Even more crucially, given philosophers' initial interest in moral deviance in narratives and imaginings, a morally deviant proposition might evoke imaginative resistance in some genres but not others.

An open question remains regarding the extent to which genre and context can be integrated into the frameworks discussed earlier. For an example of an affirmative answer, Weinberg (2008) explicitly modifies the earlier account in Weinberg and Meskin (2006) to accommodate the role of genre. Recall that on Weinberg and Meskin's original view, imagination is standardly connected to both an input system that takes in the explicitly stipulated moral deviance and a moral system that makes independent judgments using relevant nonmoral features of the fictional scenario. According to Weinberg, genre recognition can eliminate a psychological conflict between those two systems by temporarily suspending the connection between imagination and the moral system.

\subsection{Empirical Investigations}

The second challenge that recent works pose concerns methodology. In traditional discussions of imaginative resistance, philosophers often rely on introspective reports of what they find difficult to imagine, difficult to accept as fictional, and phenomenologically jarring. This reliance on introspective reports may be one reason why, as we noted earlier, there remain substantial disagreements about the scope of imaginative resistance.

Liao and Gendler (2011) suggest that one place to look for empirical support for resistance phenomena is in the psychological literature on transportation. To be transported is, roughly, to feel immersed in a fictional world, so much so that the real world temporarily ceases to feel accessible. One might think of imaginative resistance as an extreme case of transportation failure. If so, then the empirical psychological literature on transportation offers a resource for philosophers to broaden their evidential base regarding the problem of imaginative resistance. Another place to look for empirical support, especially with respect to the fictionality 
puzzle, is the burgeoning developmental psychology literature on how young children construct rich story worlds from the limited information explicitly expressed in narratives (Skolnick and Bloom 2006, Woolley and Cox 2007, Weisberg and Bloom 2009, Weisberg and Goldstein 2009, Cook and Sobel 2011, Weisberg and Sobel 2012, Weisberg et al. 2013). However, there is a notable limitation to the extant psychological literature: psychologists simply have not focused on responses to the kind of propositions that have interested philosophers, such as propositions regarding moral deviance.

More directly, in recent years, a number of philosophers have looked to empirical psychological methods to (1) test the robustness of responses to alleged cases of imaginative resistance, and (2) uncover factors that drive imaginative resistance that may be more difficult to introspectively access. The empirical turn in the development of the imaginative resistance literature is thus a nod to both the limitations of human introspection (cf. Nisbett and Wilson 1977) and the recent experimental approaches in philosophy (cf. papers collected in Nichols and Knobe 2008). Preliminarily results suggest that ordinary people do experience something like imaginative resistance in response to the cases philosophers have discussed, and that genre is one factor that moderates their responses. ${ }^{5}$

\section{Broader Implications}

In addition to its intrinsic interest, the problem of imaginative resistance also promises to shed light on issues in moral psychology, cognitive architecture, and modal epistemology. In this section, we review some of these purported implications. It is important to remember, though, that many of these suggestions are based on First Wave responses to the problem of imaginative resistance and may need to be rethought in light of Second Wave responses.

\subsection{Moral Psychology and Metaethics}

As John Doris and Stephen Stich (2012) write in their Stanford Encyclopedia of Philosophy entry: "Moral psychology investigates human functioning in moral contexts, and asks how these results may impact debate in ethical theory." In this respect, moral psychology can function as a constraint on metaethics, or theorizing about the nature of morality.

Given that prompting a subject to imagine moral deviance is a paradigmatic route to evoking imaginative resistance, the phenomenon is ripe for moral psychological exploration. The moral psychological findings, in turn, promise greater metaethical understandings. We now look briefly at two attempts to draw out metaethical conclusions from First Wave diagnoses of imaginative resistance. In our view,

\footnotetext{
${ }^{5}$ Researchers who have engaged in this line of inquiry include Stuart Brock and Marc Wilson; Sydney Levine; and Shen-yi Liao, Nina Strohminger, and Chandra Sekhar Sripada.
} 
revisiting these alleged metaethical implications of imaginative resistance in light of Second Wave works should prove to be fruitful. ${ }^{6}$

First example: Neil Levy (2005)'s metaethical conclusion takes inspiration from Weatherson's and Yablo's cantian theories. On one widely-held metaethical view, which Levy opposes, the fundamentality of the moral/conventional distinction is taken as evidence for morality's innateness, universality, and objectivity. (The moral/conventional distinction refers to the fact that typically-developing children and non-psychopathic adults respond differently to moral wrongs, such as hitting, than to conventional wrongs, such as wearing pajamas to school.) In response, Levy argues that imaginative resistance shows that the moral/conventional distinction is in fact parasitic on a more fundamental psychological distinction, between authority-independent and authority-dependent concepts. This distinction between authority-independent and authority-dependent concepts is an extension of Weatherson's and Yablo's diagnoses of imaginative resistance, which identify not only moral deviances, but also nonmoral deviances, as sources of imaginative resistance. That is, with cases of imaginative resistance, people respond to moral deviances in the same way that they respond to deviances with other authorityindependent concepts. So, argues Levy, only a focus on authority-independent concepts, which includes both moral and nonmoral concepts, can give a unifying explanation of imaginative resistance. The different patterns of responses to moral/conventional concepts that psychologists have picked out are, in fact, just parts of larger patterns of responses to authority-independent/authority-dependent concepts. Since the moral/conventional distinction is not psychologically fundamental, argues Levy, it cannot be considered evidence for morality's innateness, universality, and objectivity.

Second example: Julia Driver (2008)'s metaethical conclusion takes inspiration primarily from Gendler's wontian theory, supplemented by insights from Weatherson's cantian theory. Driver aims to defend Humean sentimentalism, which says that sentiments make our moral beliefs psychologically necessary for us. Opponents of Humean sentimentalism have criticized the view for relying on the elusive notion of psychological necessity. Drawing on Gendler's and Weatherson's diagnoses, Driver argues that imaginative resistance helps us to get a handle on this notion, and provides support for Humean sentimentalism. In short, the comparative difficulty people experience when prompted to imagine morally deviant fictional worlds, contends Driver, points to the psychological necessity of our moral commitments.

\footnotetext{
${ }^{6}$ Stueber (2011) and Kennett (2011) represent recent efforts that give more due to the importance of context in diagnosing imaginative resistance and drawing out metaethical conclusions from it.
} 


\subsection{Moral Psychology and Aesthetic Psychology}

Since Plato and Aristotle, philosophers have wondered about the relationships between moral psychology and aesthetic psychology, or human functioning in aesthetic contexts. One thread of discussion is concerned with moral persuasionthe capacity of fictions to morally educate and corrupt. Another thread of discussion is concerned with ethical criticism of art-the legitimacy of criticizing an artwork on moral grounds. These two threads are closely intertwined with one other, and with the problem of imaginative resistance.

A prominent position in the ethical criticism of art debate is moralism, the view that a moral defect of an artwork can constitute an aesthetic defect of the work. A persistent challenge for this position is to explain why this is so. Nöel Carroll (1998) proposes a psychological link: if the moral perspective of the work prevents an audience from becoming properly engaged by the work, the work is thereby aesthetically blemished.

Numerous philosophers have drawn together moral persuasion and imaginative resistance to articulate and substantiate Carroll's psychological hypothesis (Mullin 2004, Harold 2005, Dadlez 2005; Smuts 2006 broadens the scope to include also how a fiction conveys its message; see also a partial dissent in Hazlett 2009). As Plato and Aristotle were aware, imaginative engagement with fictions can shape our real-world moral views, for better or for worse. (Gendler $(2003,2006 \mathrm{~b})$ refers to this phenomenon as imaginative contagion.) Hence, when prompted to imagine moral deviance, people may resist out of the perceived risk that their real-world moral views may be worsened as a result. When a psychologically typical audience is prevented from engaging with the work, the work's propensity to evoke such resistance constitutes an aesthetic defect. Thus imaginative resistance serves as the missing link between moral deviance and aesthetic blemish.

Recent discussions of these issues have, in line with Second Wave works on imaginative resistance, pointed out that earlier authors have not sufficiently accounted for the importance of context in their discussions of moral persuasion and ethical criticism of art. Joshua Landy (2008), for instance, notes that people appear to not experience imaginative resistance with moral deviances in films like Goodfellas. A.W. Eaton (2012) goes further and argues for immoralism, the view that moral defects of a work can constitute aesthetic virtues. Specifically, Eaton argues that the fact that people do not experience imaginative resistance toward some moral deviances signify a kind of artistic achievement, of taking the audience past the initial jarring reaction-what we have called "hermeneutic recalibration" (cf. Harold 2007). Shen-yi Liao (2013) argues that whether imagining moral deviances will worsen one's real-world moral views significantly depends on genre. In satires, for example, imagining moral deviances can in fact improve one's real-world moral views. 


\subsection{Cognitive Architecture}

Cognitive architecture refers to the formal structure of the mind at the cognitive or functional level. Despite some notable naysayers (Churchland 1981), many philosophers have found it fruitful to theorize about the mind at the functional level-that is, talking about propositional attitudes, modules, and their inputs and outputs-even if a wholesale functionalism proves to be untenable. Traditional philosophical discussion of cognitive architecture has been centered on belief, desire, and intentions; recent discussions have explored if and how propositional imagination might fit into such a framework (cf. papers collected in Nichols (2006b)).

We have already mentioned two such attempts at drawing architectural lessons on the basis of imaginative resistance diagnoses. Weinberg and Meskin (2006) and Weinberg (2008) maintain that propositional imagination functions much like belief, except (1) it is connected to an inputter, which can take in non-truth-directed information, and (2) its connection to the moral system can be attenuated by genre cues. And Currie (2002) and Stokes (2006) maintain that imaginative resistance shows the necessity of positing an additional imaginative attitude that is conative, analogous to first- and second-order desires respectively (cf. Doggett and Egan 2007, 2011).

Elisabeth Camp (manuscript 2009) argues that a unifying solution to the problem of imaginative resistance and two other puzzles-concerning fictional emotions and disparate responses to fictional and actual scenarios-demands the recognition of the perspectival nature of imagination. In emphasizing the role of a perspective in imagination, Camp picks up an earlier discussion of imaginative resistance by Richard Moran (1994).

Gendler (2008a, 2008b, 2012) has argued that imaginative contagion, whereby imaginative engagement with fictions can reshape our real-world moral views, may be traceable to a cognitive state that she has dubbed alief. Aliefs are, roughly, innate or habitual propensities to respond to apparent stimuli in automatic and associative ways. Alief-driven responses may be in tension with those that arise from one's explicit beliefs and desires. So, for example, while a subject may believe that eating a piece of feces-shaped chocolate is completely safe, she may nonetheless show hesitation at the prospect because the shape and color renders occurrent an alief with the content "filthy object, disgusting, stay away". Since aliefs, by their nature, are source-indifferent, imagined content may give rise to alief-driven reactions. As a result, the notion of alief may explain how content that we explicitly recognize to be purely imaginary may nonetheless produce powerful emotional and cognitive responses of the sort that underpin imaginative contagion. In this light, aliefs can be seen as an implementation of Gendler's wontian theory in cognitive architectural terms. 


\subsection{Modal Epistemology}

Modal epistemologists aim to answer whether and how we can have justification in our claims about what is metaphysically, or conceptually, or "absolutely" possible. A longstanding question in modal epistemology is on the extent to which imaginability-and its cousin conceivability-can serve as guides to metaphysical possibility (cf. papers collected in Gendler and Hawthorne 2002). Since imaginative resistance appears to point to surprising limitations of imagination, some philosophers have attempted to elucidate its implications for modal epistemology.

Peter Kung (2010) thinks imaginative resistance should make us pessimistic about modal epistemology. In order to outline imagination's limitations, Kung surveys three responses to the problem of imaginative resistance: Weatherson's and Yablo's cantian theories, Currie's and Stokes's wontian theories, and Kung's own certainty theory-on which one cannot imagine what one is epistemically certain to be false. On all of these diagnoses, imagination's limitations come from either prior knowledge (in the case of cantian and certainty theories) or epistemically irrelevant factors (in the case of wontian theories). So, Kung concludes, the sort of restrictions on the imagination that imaginative resistance points to cannot function as new and independent evidence for modal knowledge. Imagination's limitations are therefore poor guides to metaphysical impossibilities.

Janet Levin (2012), by contrast, thinks imaginative resistance should make us cautiously optimistic about modal epistemology. While she concedes that the sort of restrictions on the imagination that imaginative resistance highlights fail as indicators of conceptual impossibilities, she maintains that attention to imaginative resistance can prevent our modal epistemology from being led astray. Specifically, if we can rule out that an apparent instance of unimaginability can be traced to imaginative resistance, then we have prima facie reason to think that the unimaginability is a good indicator of conceptual impossibility. She also distinguishes temporary imaginative resistance (what we have called "hermeneutic recalibration") from the persistent variety. When one overcomes temporary imaginative resistance and is able to imagine a scenario as a coherent whole, one then has reason to think that the imaginability there is a good indicator of conceptual possibility (modulo other cognitive limitations that we must be attentive to). From the perspective of modal epistemology, temporary imaginative resistance acts as a prompt for looking further into potentially problematic features of a hypothetical scenario.

\section{Future Directions}

In this chapter, we have given an introduction to the problem of imaginative resistance and recounted the upstream and downstream debates that it has spurred. In the process, we have pointed out connections and tensions between various extant 
discussions. These connections and tensions, in turn, point to places where progress can be made, including:

- Exploring other sources of contextual differences, such as cultural and individual variations, in characterizing and explaining imaginative resistance.

- Examining the problem of imaginative resistance using methods of cognitive science.

- Integrating insights from First and Second Wave diagnoses of imaginative resistance.

- Reevaluating imaginative resistance's purported implications for issues in moral psychology, cognitive architecture, and modal epistemology in light of the Second Wave works.

- Integrating insights from discussions of imaginative resistance into broader discussions of the role of imagination in philosophy, the relation between rational and non-rational persuasion, the nature of narrative, and the relation between philosophy and literature. 


\section{References}

Brock, S. (2012), "The puzzle of imaginative failure," The Philosophical Quarterly 62: 443-463.

Camp, E. (manuscript 2009) "Perspectives in imaginative engagement with fiction," unpublished manuscript. URL $=<$ http://philpapers.org/rec/CAMPII $>$

Carroll, N. (1998) “Moderate moralism versus moderate autonomism," British Journal of Aesthetics 38(4): 419-424.

Churchland, P.M. (1981) "Eliminative materialism and the propositional attitudes," Journal of Philosophy 78: 67-90.

Cook, C., and Sobel, D.M. (2011) "Children's beliefs about the fantasy/reality status of hypothesized machines," Developmental Science 14(1): 1-8.

Currie, G. (2002) “Desire in imagination,” in Gendler and Hawthorne (2002).

Dadlez, E.M. (2005) "Spectacularly bad: Hume and Aristotle on tragic spectacle," The Journal of Aesthetics and Art Criticism 63(4): 353-358.

Doggett, T., and Egan, A. (2007) "Wanting Things You Don't Want: the Case for an Imaginative Analogue of Desire," Philosophers' Imprint 7(9): 1-17.

Doggett, T., and Egan, A. (2011) "How We Feel about Terrible, Non-existent Mafiosi," Philosophy and Phenomenological Research 84(2): 277-206.

Doris, J., and Stich, S. (2012) "Moral Psychology: Empirical Approaches," in Zalta, E.N., editor, Stanford Encyclopedia of Philosophy. Stanford: Center for the Study of Language and Information, Stanford University. Winter 2012 edition. URL $=<$ http://plato.stanford.edu/archives/win2012/entries/moral-psych$\mathrm{emp} />$.

Driver, J. (2008) "Imaginative resistance and psychological necessity," Social Philosophy and Policy 25(1): 301-313.

Eaton, A.W. (2012) "Robust immoralism," The Journal of Aesthetics and Art Criticism 70(3): 281-292.

Gendler, T.S. (2000) “The puzzle of imaginative resistance," The Journal of Philosophy 97(2): 55-81. 
Gendler, T.S. (2003) "On the relation between pretense and belief," in Kieran and Lopes (2003).

Gendler, T.S. (2006a) “Imaginative resistance revisited," in Nichols (2006b).

Gendler, T.S. (2006b) “Imaginative contagion,” Metaphilosophy 37(2): 1-21.

Gendler, T.S. (2008a) “Alief and belief,” The Journal of Philosophy 105(10): 634-663.

Gendler, T.S. (2008b) “Alief in action (and reaction)," Mind and Language 23(5): 552-585.

Gendler, T.S. (2009) "Imaginative resistance," in Davies, S., Higgins, K.M., Hopkins, R., Stecker, R., and Cooper, D.E., editors, A Companion to Aesthetics: Second Edition. New York: Blackwell.

Gendler, T.S. (2012) "Between Reflex and Reason: Response to Commentators," Analysis 72(4): 799-811.

Gendler, T.S., and Hawthorne, J., editors (2002) Conceivability and Possibility. New York: Oxford University Press.

Harold, J. (2005) “Infected by evil,” Philosophical Explorations 8(2): 173-187.

Harold, J. (2007) “The ethics of non-realist fiction: Morality's Catch-22," Philosophia 35: 145-159.

Hazlett, A. (2009) "How to defend response moralism," British Journal of Aesthetics 49(3): 241-255.

Hume, D. (1757) "Of the standard of taste," in Essays: Moral, Political and Literary (1875), London: Longmans, Green, and Co.

Kennett, J. (2011) “Imagining reasons," The Southern Journal of Philosophy, 49(Spindel Supplement): 181-192.

Kieran, M., and Lopes, D. M., editors (2003) Imagination, Philosophy, and the Arts. New York: Routledge.

Kung, P. (2010) "Imagining as a guide to possibility," Philosophy and Phenomenological Research 81(3): 620-663.

Landy, J. (2008) "A nation of Madame Bovarys: On the possibility and desirability of moral improvement through fiction," in Hagberg, G.L., editor, Art and Ethical Criticism. Malden, MA: Blackwell. 
Levin, J. (2012) "Imaginability, possibility, and the puzzle of imaginative resistance," Canadian Journal of Philosophy 41(3): 391-422.

Levy, N. (2005) "Imaginative resistance and the moral/conventional distinction," Philosophical Psychology 18(2): 231-241.

Lewis, D.K. (1989) “Dispositional Theories of Value (II)," Proceedings of the Aristotelian Society 63: 113-137.

Liao, S. (2011) On Morals, Fictions, and Genres. PhD thesis, University of Michigan, Ann Arbor.

Liao, S. (2013) "Moral Persuasion and the Diversity of Fictions," Pacific Philosophical Quarterly 94(2): 269-289.

Liao, S., and Gendler, T.S. (2011) "Pretense and imagination," Wiley Interdisciplinary Reviews: Cognitive Science 2(1): 79-94.

Matravers, D. (2003) "Fictional assent and the (so-called) 'puzzle of imaginative resistance'," in Kieran and Lopes (2003).

Moran, R. (1994) “The expression of feeling in imagination," The Philosophical Review 103(1): 75-106.

Mothersill, M. (2003) "Make-believe morality and fictional worlds," in Bermúdez, J.L., and Gardner, S., editors, Arts and Morality. New York: Routledge.

Mullin, A. (2004) "Moral defects, aesthetic defects, and the imagination," The Journal of Aesthetics and Art Criticism 62(3): 249-261.

Nanay, B. (2010) "Imaginative resistance and conversational implicatures," The Philosophical Quarterly 60: 586-600.

Nichols, S. (2004) "Imagining and believing: the promise of a single code," The Journal of Aesthetics and Art Criticism 62(2): 129-139.

Nichols, S. (2006a). “Just the imagination: Why imagining doesn't behave like believing," Mind and Language 21: 459-474.

Nichols, S., editor (2006b) The Architecture of the Imagination. New York: Oxford University Press.

Nichols, S., and Knobe, J., editors (2008) Experimental Philosophy. New York: Oxford University Press. 
Nichols, S., and Stich, S. (2003) Mindreading. New York: Oxford University Press.

Nisbett, R.E., and Wilson, T.D. (1977) "Telling more than we can know: Verbal reports on mental processes," Psychological Review 84(3): 231-259.

Skolnick, D., and Bloom, P. (2006) "What does Batman think about SpongeBob? Children's understanding of the fantasy/fantasy distinction," Cognition 101: B9-B18.

Smuts, A. (2006) "V. F. Perkins' functional credibility and the problem of imaginative Resistance," Film and Philosophy 10: 85-99.

Stock, K. (2005) “Resisting imaginative resistance,” The Philosophical Quarterly 55: 607-624.

Stokes, D. (2006) "The evaluative character of imaginative resistance," British Journal of Aesthetics 46(4): 387-405.

Stueber, K.R. (2011). "Imagination, empathy, and moral deliberation: the case of imaginative resistance," The Southern Journal of Philosophy 49(Spindel Supplement): 156-180.

Tanner, M. (1994). "Morals in fiction and fictional morality (II)," Supplement to the Proceedings of the Aristotelian Society 68: 51-66.

Todd, C. (2009) "Imaginability, morality, and fictional truth: Dissolving the puzzle of 'imaginative resistance,", Philosophical Studies 143(2): 187-211.

Walton, K.L. (1990). Mimesis as Make-Believe. Cambridge, MA: Harvard University Press.

Walton, K.L. (1994) "Morals in fiction and fictional morality (I)," Supplement to the Proceedings of the Aristotelian Society 68: 27-50.

Walton, K.L. (2006) "On the (so-called) puzzle of imaginative resistance," in Nichols (2006b).

Weatherson, B. (2004) “Morality, fiction, and possibility," Philosophers' Imprint 4(3): $1-27$.

Weisberg, D.S., and Bloom, P. (2009) "Young children separate multiple pretend worlds," Developmental Science 12(5): 699-705. 
Weisberg, D.S., and Goodstein, J. (2009) "What belongs in a fictional world?" Journal of Cognition and Culture 9: 69-78.

Weisberg, D.S., and Sobel, D.M. (2012) "Young children discriminate improbably from impossible events in fiction," Cognitive Development 27: 90-98.

Weisberg, D.S., Sobel, D.M., Goodstein, J., and Bloom, P. (2013) "Young children are reality-prone when thinking about stories," Journal of Cognition and Culture 13: 282-407.

Weinberg, J.M. (2008) "Configuring the cognitive imagination," in Stock, K., and Thomsen-Jones, K., editors, New Waves in Aesthetics. New York: Palgrave Macmillan.

Weinberg, J.M., and Meskin, A. (2006) "Puzzling over the imagination: Philosophical problems, architectural solutions," in Nichols (2006b).

Willard, M.B. (manuscript 2013) "Stop over-analyzing it: the puzzle of historical inaccuracy and the pragmatic interpretation of imaginative resistance," unpublished manuscript.

Woolley, J.D., and Cox, V. (2007) "Development of beliefs about storybook reality," Developmental Science 10: 681-693.

Yablo, S. (2002) “Coulda, woulda, shoulda," in Gendler and Hawthorne (2002). 


\section{Further Readings}

Bartel, C. (2012) "The Puzzle of Historical Criticism," The Journal of Aesthetics and Art Criticism 70(2): 213-222.

de Sousa, R. (2010) “The mind's Bermuda Triangle: Philosophy of emotions and empirical science," in Goldie, P., editor, The Oxford Handbook of Philosophy of Emotion. New York: Oxford University Press.

Gendler, T.S. (2011) "Imagination," in Zalta, E.N., editor, Stanford Encyclopedia of Philosophy. Stanford: Center for the Study of Language and Information, Stanford University. Spring 2011 edition. URL = $<$ http://plato.stanford.edu/archives/fall2011/entries/imagination/>.

Mahtani, A. (2012) "Imaginative resistance without conflict," Philosophical Studies 158(3): 415-429.

Stock, K. (2003) “The Tower of Goldbach and other impossible tales," in Kieran and Lopes (2003). 